\title{
A MODERNIDADE SEGUNDO WALTER BENJAMIN
}

Willi Bolle(1)

RESUMO: $O$ Trabalho das Passagens (192740), de Walter Benjamin, é interpretado como expressão da experiência do escritor autônomo na República de Weimar e nos primeiros anos do Terceiro Reich. A ambigüidade de sua situação histórica é mostrada no confronto entre formas de expressão da re volta $e$ o condicionamento pelo mercado literário. Uma montagem critica lou radiografia) de gêneros literários urbanos - feuilleton, historia de detetive, poesia do apache revela as fantasmagorias da pequena-burguesia contra o fundo de suas condiçóes de vida reais.

\begin{abstract}
Benjamin's Passagenwerk is taken as the expression of the autonomous writer's experience during the Weimar Republic and the first years of the Third Reich. The ambiguity of his historical situation becomes clear within the confrontation between the literary forms of rebellion and the conditions dictated by the literary market. A critical set up (or a radiography) of urban literary genders - feuilleton, detective story, apache's poetry - unveils the delusions of middle-classes against the background of their real life conditions.
\end{abstract}

Um ensaio exemplar sobre a Modernidade completará, em breve, meio século de existência: trata-se de $A$ Paris do Segundo Império em Baudelaire, escrito por Walter Benjamin em 1938. É um modelo em miniatura de uma obra maior, mas inacabada - o Trabalho das Passagens ou Passagens Parisienses (1927-40) - , que representa, juntamente com Origem do Drama Barroco Alemão (1928), a obra de maior peso do filósofo, crítico e escritor alemão. Motivo de controvérsia entre Benjamin e Adorno, o ensaio foi recusado para a publicação em 1938 e só veio a público em 1969. Na época, Benjamin se viu obrigado a reescrever o trabalho, de que resultou Sobre Alguns Motivos em Baudelaire (1939). Do Trabalho das Passagens, esses dois ensaios são os únicos textos acabados; no mais, existem o resumo Paris, Capital do Século XIX lem duas versões, a alemã, de 1935, e a francesa, de 1939), um volumoso conjunto de fragmentos, esboços, notas e materiais, e alguns ensaios complementares: A Obra de Arte na Era de Sua Reprodutibilidade Técnica (1935), Eduard Fuchs, o Colecionador e o Historiador (1937) e as Teses Sobre o Conceito da História (1940).

0 projeto benjaminiano da Modernidade será apresentado aqui em forma de um sucinto comentário de A Paris do Segundo Império em Baudelaire e Sobre Alguns Motivos em Baudelaire. Entre os estudiosos brasileiros, KOTHE (1978) focalizou as diferenças entre esses dois ensaios, no sentido de um confronto entre as concepções de Benjamin e Adorno; ROUANET (1987) comparou as duas versões de

(1) Professor Adjunto do Departamento de Letras Modernas da FFLCH-USP. 


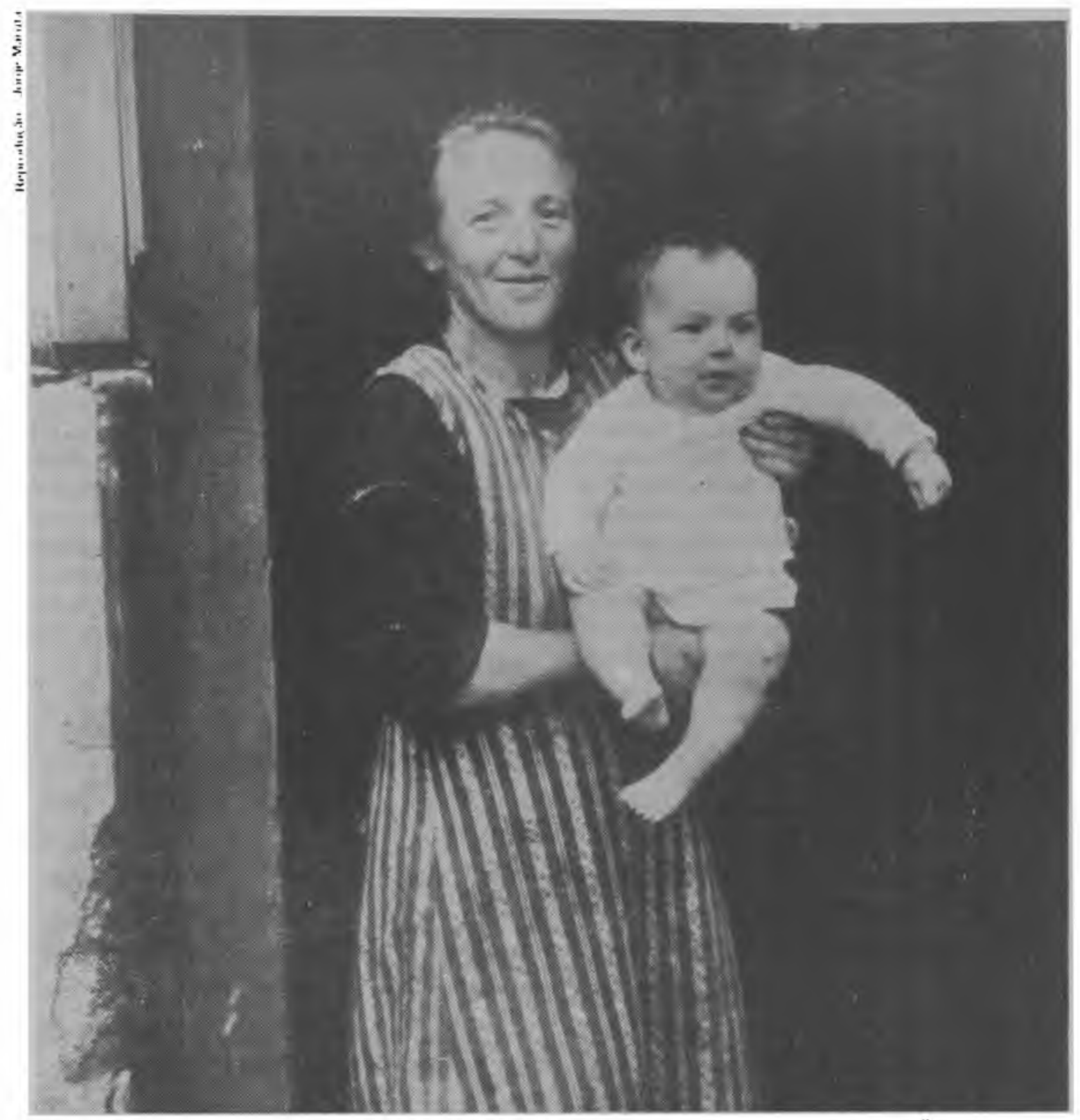

Foto 1. Mãe operária com seu filho, por volta de 1928. *

Paris, Capital do Século $X I X$, agrupando em relação a elas os numerosos materiais e notas do Trabalho das Passagens publicados em 1982. O presente estudo se propõe ler os ensaios de BENJAMIN (1938 e 1939) dentro de uma perspectiva histórica, assim definida pelo autor: Não se trata de apresentar as obras literárias em correlação com seu tempo, e sim, apresentar - no tempo em que elas nasceram - o tempo que as conhece: o nosso. Falar da Modernidade de Baudelaire significava, para Benjamin, expressar a experiência de sua própria geração: o trabalho do escritor na República de Weimar e nos primeiros anos do Terceiro Reich.

* As fotos foram tiradas de SANDER, A. Antlitz der Zeit, (Fisionomia da época), ed. original: 1929; reimpressão: Ed. Schirmer-Mosel, 1983.

46 - REVISTA USP 


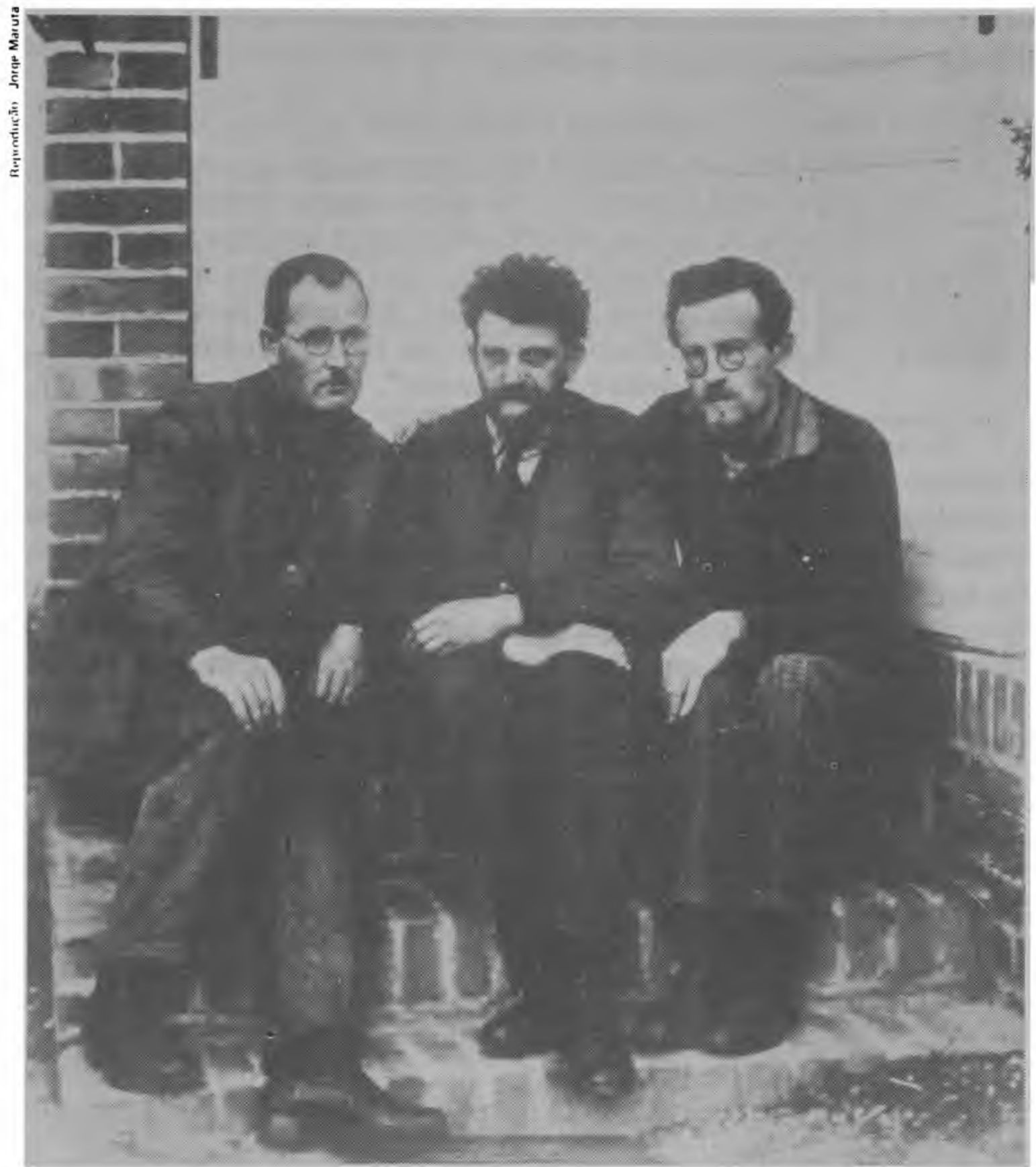

Foto 2. Revolucionários 1928.

\section{Situação do Escritor}

O sentido geral do trabalho de Benjamin, durante as décadas de 20 e 30, foi a reflexão sobre a condição do escritor e do intelectual: sua posição, seu papel, sua função social. O tema prioritário de Benjamin, naqueles conturbados anos, foi a crise econômica e política do escritor autônomo - o homem de letras obrigado a viver de seu trabalho e, portanto, envolvido na crise geral. O ensaio sobre Baudelaire mostra a origem histórica do escritor moderno, no ambiente social da bohème e na roupagem alegórica do flâneur (São esses os títulos dos 
capítulos 1 e 2 do ensaio de 1938.). Já no primeiro resumo do TrabaTho das Passagens, Benjamin explicara:

"Com o flâneur, a inteligência literária entra no mercado. Na fase intermediária em que ela ainda tem mecenas, mas já começa a se familiarizar com o mercado, ela aparece como bohème. $A$ indeterminação de sua posição econômica corresponde a indeterminação de sua função política. Isso se mostra de maneira mais clara nos conspiradores profissionais, todos eles pertencentes à bohème. A poesia de Baudelaire tira sua força do páthos rebelde dessa camada social"

Essas palavras circunscrevem a esfera de atuação do escritor profissional na sociedade burguesa de mercado. Suas contradições - a indeterminação econômica e a ambigüidade política - e as de sua classe de origem são estudadas no campo de tensão entre as formas de expressão da revolta e o condicionamento pelo mercado: o feuilleton dos jornais. Ambígua é também a atitude geral de Benjamin em relação a Baudelaire: um jogo entre identificação e distanciamento, (auto-) ironia romântica como forma de autoconhecimento. Foi com os primeiros românticos alemães, Friedrich Schlegel e Novalis, que

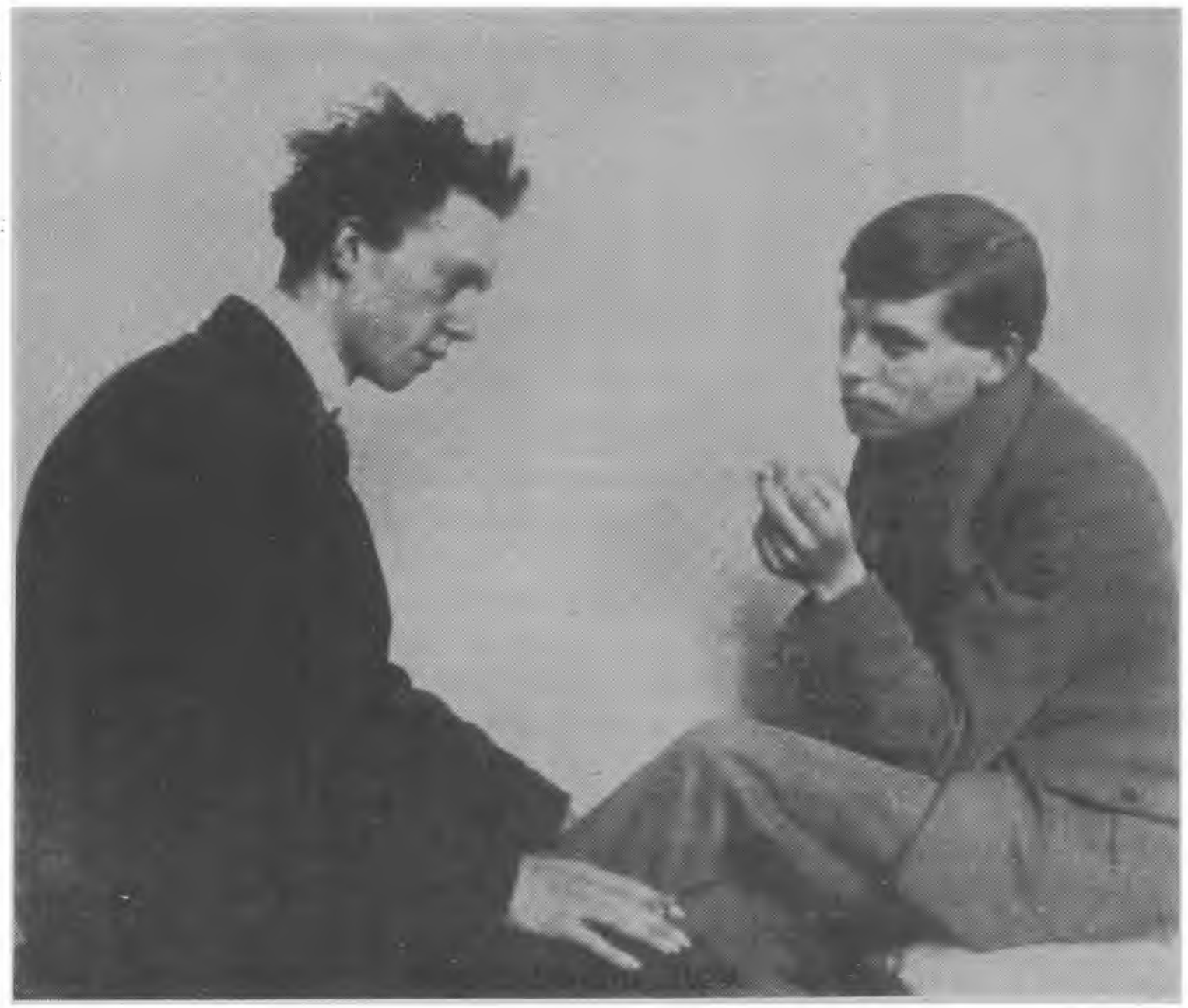


Benjamin aprendeu o ofício da crítica; ele o adapta para a Modernidade alemã dos anos 1920 e 30.

Um estado geral de revolta contra a sociedade existente caracterizava toda essa massa indefinida, caótica, jogada para cá e para lá, chamada pelos franceses de bohème, estado de ânimo que se traduziu em determinadas formas literárias. Como metáfora do trabalho do escritor, aparece em Baudelaire a figura do lixeiro. Benjamin completa as metáforas do poeta-engenheiro (Edgar A. Poe) e do poeta-operário (Maiakóvski) por uma imagem tirada do mais baixo degrau da escala social:

"Do literato ao conspirador profissional, cada qual que pertencia à bohème podia reencontrar no lixeiro um pedaço de si"

A concepção desiludida da Modernidade alemã - em que pesam a experiência da inflação de 1923 e da conseqüente pauperização - leva o crítico a comentar sarcasticamente os pesquisadores do pauperismo, empenhados em descobrir onde estaria o limite da miséria humana.

Da representação baudelaireana dos de baixo - pobres, socialmente desprezados e os que não possuem nada - Benjamin dirige o olhar para os de cima, perguntando qual a posição do escritor em relação aos donos do poder. Baudelaire, depois de ter superado atitudes iniciais de humor macabro, desejo terrorista e culte de la blague que, na época de Benjamin, acabaram sendo encampados pela propaganda fascista - elaborou um código próprio de revolta com o satanismo, forma teológica radical, que constitui uma resposta à altura do cinismo da classe dominante. Resumindo o caráter da poesia social de Baudelaire, Benjamin caracteriza-a em termos de uma profunda duplicidade:

" ela toma o partido dos oprimidos, tanto de suas ilusões quanto de sua causa"

De que meios de comunicação dispõem o poeta e o crítico para expressar o espírito de revolta? Com a expansão da economia burguesa, as belas letras ganharam, como observa Benjamin, um considerável mercado de vendas no feuilleton, inventado por volta de 1840 pór Girardin, editor do jornal La Presse. O subtexto de uma série de considerações benjaminianas sobre o feuilleton é, sem dúvida, a experiência vivida nos anos 1926-33 no jornal Die Literarische Welt (editor: Willy Haas) e no feuilleton do Frankfurter Zeitung (cujo redator era Siegfried Kracauer). A visão desiludida do mercado literário faz com que a literatura seja considerada como mercadoria, a atividade literária medida pelo seu preço, e o trabalho do escritor apresentado sob o 
aspecto pouco vantajoso dá prostituição: Confrontar o literato $-e$ em primeiro lugar, a si mesmo, com a prostituta, era normal para Baudelaire. Entre os outros literatos que mereceram tal epíteto, Benjamin cita um comentário de Baudelaire sobre Lamartine, escritor muito bem remunerado a serviço da política oficial.

Ver a honrosa cultura desta maneira rebaixada para a esfera dos lixeiros e dos lúmpens, dos marginais e das prostitutas - podia ser sentido como desacato por alguns representantes da cultura. Talvez isso tenha pesado na censura do ensaio de Benjamin por Adorno e Horkheimer. Nessa hipótese, a provocação não era apenas o satanismo de Baudelaire nem o marxismo de Benjamin, mas uma crítica arrasadora da cultura. Escrever a história significa, porém, como diz o ensaista, dar aos anos uma fisionomia. O ano era 1938. A Alemanha, dirigida então por elementos do submundo, tinha liquidado com o melhor de sua cultura e estava prestes a começar uma nova guerra.

\section{Gêneros literários urbanos}

O que caracteriza o estilo feuilleton, essa grande escola jornal ística, urbana, onde aprendia, por volta de 1840, a geração de Baudelaire e onde ingressava, em 1926, o crítico Walter Benjamin? A função do feuilleton era, numa frase: apresentar uma revista colossal do mundo burguês. Nesse sentido, o feuilleton era parente das fisiologias do século XIX e precursor das atuais revistas ilustradas e gêneros afins. Essa literatura é, antes de mais nada, preenchimento de linhas, ocupação de todo o espaço disponivel; um trabalho da mídia que, no caso negativo - Benjamin cita o testemunho crítico do jornalista Karl Kraus - "calafeta os acontecimentos em relação à experiência palpável do leitor", diminui portanto sua experiência, paralisa a imaginação, liquida com a memória. Para cumprir a função de construir uma enorme e ininterrupta fantasmagoria, o procedimento do feuilleton consiste em transformar o boulevard em intérieur, assim como a rua se torna morada para o flâneur. Procura-se estabelecer uma fantástica harmonia entre a esfera particular burguesa e a cultura de rua. O trabalho do crítico-escritor consiste em desmontar esse harmonioso sonho.

Como a poética de Baudelaire, também a ensaística de Benjamin se distancia da feitura neofisiognômica do estilo feuilleton e de suas imagens urbanas idílicas, partindo para uma transformação. $O$ pressuposto da inocuidade - a transmissão de uma imagem amigável das relações interpessoais - é contestado em nome de uma observação da realidade metropolitana, onde as pessoas se conhecem como devedores e credores, vendedores e clientes, patrões e empregados e, sobre- 
tudo, como concorrentes. A figura do choque começa a se delinear no estilo do ensaísta, que aposta numa literatura que fixa os aspectos inquietantes $e$ ameaçadores da vida urbana. Para falar da luta entre concorrentes, dos interesses individuais em jogo, das funções da massa na grande cidade, é necessário um instrumento literário mais exato: a história de detetive, gênero inventado por Edgar A. Poe na década de 1840 e assimilado por Baudelaire através de suas traduções. Para Benjamin, o novo gênero - além de vantagens técnicas - observação aguda e exatidão de uma narrativa científica - permite, pela própria essência, focalizar a vida urbana no seu aspecto ameaçador e perigoso: a Cidade como lugar do Crime.

Contudo, a história de detetive não é simplesmente adotada e assimilada pelo poeta e pelo ensaísta, mas sofre marcantes mudanças de funções. Baudelaire não escreveu nenhuma história de detetive, porque a identificação com o detetive Ihe era incompativel. Diferentemente de Poe, cuja simpatia era com o detetive, o momento construtivo em Baudelaire se inclinava para o lado dos personagens associais (logo mais falaremos de sua poesia do apache). Benjamin, para alcançar seu objetivo maior - a fisionomia da grande cidade contem. porânea -, aborda o gênero por uma leitura às avessas, cujo /eitmotiv é brechtiano: Apague as pegadas (refrão de um famoso poema da Cartilha para habitantes das cidades, escrita por Brecht em 1926). Como conteúdo social original da história de detetive, o crítico postula $o$ apagar as pegadas do indivíduo na multidão. Paradoxo que se esclarece quando essa leitura nos faz perceber notáveis contradições sociais. Pois a burguesia, como detentora do sistema administrativo de controle, pratica ela mesma um comportamento associal: sua cultura de moradia é interpretada por Benjamin como defesa contra o controle.

No momento em que o lugar social do Bem e do Mal começa a ser questionado dessa maneira, a história de detetive ou narrativa policial chega a seus limites. De fato, o gênero sofre grandes transformações de que são testemunhas, na época em questão, os romances de Doeblin e de Brecht. Mas, voltando a Benjamin: para esclarecer as referidas contradições, ele precisava de um instrumento mais exato, mais aperfeiçoado que a história de detetive. Ele o chama de "radiografia da história de detetive" citando como exemplo concreto o conto de Poe, O Homem das multidões. Tocamos aqui o cerne da intenção benjaminiana: Transformar a narrativa cientifica num ensaio radiográfico da Modernidade. O discurso benjaminiano da Modernidade é uma radiografia da metrópole moderna, organizada de tal forma que aparecem, sob as aparências manifestas, as significativas estruturas latentes.

Como se fabrica tal radiografia? quais os procedimentos em jo- 
go? Tratava-se de um work in progress, onde certos procedimentos que Benjamin havia descoberto no ensaio de 1938 foram esclarecidos melhor em seu trabalho de 1939. De um modo geral, podemos dizer que a apresentação benjaminiana se move no campo de tensão entre a esfera da fantasmagoria e a sobriedade. Dos surrealistas, Benjamin assimila os elementos de devaneio, sonho e êxtase, confrontando-os com um estranhamento sóbrio, quase brechtiano. A diferença específica em relação a Brecht consiste num procedimento que Benjamin chama de técnica de acordar Trata-se de uma compreensão mimética da mitologia moderna: o escritor penetra nas camadas da fantasmagoria coletiva - devaneio, sonho, delírio - e resgata o conhecimento desses estados inconscientes para a zona da vigília, da consciência acordada.

É uma espécie de protocolo onírico, registro ao mesmo tempo mimético e crítico dos sonhos coletivos da Modernidade. Romanticamente falạndo, uma moderna escrita adivinhatória. Como isso é feito tecnicamente? Em termos de composição, podemos falar numa ensaística cinematográfica, na medida em que Benjamin realiza uma montagem de textos sobre as condições de vida metropolitana, contrapondo aos estados oníricos, em forma de choque: instantes de máxima sobriedade.

Dentro dessa técnica geral, o artifício mais importante e mais característico é a Ueberblendung, ou seja, a fusão de duas imagens, onde do esvanecer (fading out) da primeira, surgem, cada vez mais nítidos (fading in), os contornos da segunda. Embora essa técnica se assemelhe à da superposição de imagens - por exemplo, a projeção de uma transeunte contra fundo de multidão - elas não devem ser confundidas. A superposição trabalha com a contigüidade, ela é metonímica, ao passo que a fusão trabalha com a opacidade e a transparência, ela é reveladora. Verdadeira função poética, no sentido jakobsoniano, em que a projeção do princípio de equivalência do eixo de seleção sobre o eixo de combinação tem o efeito de desmascarar.

\section{Mitos burgueses}

Um exemplo concreto: o comentário benjaminiano do conto de Poe, 0 Homem das multidões, focaliza o retrato da classe dos empregados de nível médio-superior, da seguinte maneira: "Poder-se-ia pensar que se trata de individuos semibêbados, miseráveis. Na verdade, trata-se de pessoas de boa familia, comerciantes, advogados e especuladores da bolsa de valores" A leitura do crítico projeta discretamente sobre as pessoas de boa familia, de boa condição, o véu da miséria 
geral das classes pobres. O compromisso do escritor é com a fisionomia de sua época. A meta de Poe, esclarece Benjamin, não foi a literatura que, mais tarde, seria recomendada como modelo para o realismo socialista, mas uma imaginação conscientemente deformadora.

Outro exemplo de fusão desmascaradora é a caracterização do flâneur como um abandonado no meio da multidão. Na verdade, o termo alemão, ein Preisgegebener, é ambíguo, querendo dizer ao mesmo tempo: um indivíduo que tem seu preço no meio da multidão. Aquele que olha as mercadorias, com sonhos de consumidor, é, ele mesmo, mercadoria. Só que o flâneur não sabe disso, o espírito da mercadoria penetra-o como um alucinógeno, que deve compensar suas muitas humilhações.

Com a crítica do flâneur, Benjamin atinge o mito burguês da esfera particular, para onde o indivíduo podia se retirar como que entrando em um abrigo. Tal refúgio não existe mais na Modernidade. A situação da classe dos pequenos-burgueses, de que faz parte o flâneur. é comentada pelo crítico de maneira pessimista. No século XIX, diz ele, "ela se encontrava apenas no início de seu declínio. Inevitave/mente, muitos tinham de tropeçar um dia na natureza mercantil de sua força de trabalho" Subjetivamente, a classe em questão cultiva suas fantasmagorias, objetivamente ela se proletariza (Esse, pelo menos, é o registro histórico da situação alemã nos anos 1920 e 30.). "Na melhor das hipóteses" diz ainda Benjamin, sua parte poderia ser "a fruição, jamais o poder" O conceito de história subjetivo dessa classe se reduz a um passatempo. Imensa soma de pequenos sonhos de fruição e consumo, essa classe sem projeto histórico se desintegra em átomos de subjetividade, onde cada qual permanece isolado dentro de seus interesses particulares.

Assim se esvanecem a aparência e o charme erótico que a massa tem para o consumidor médio. $E$ vem à tona a função da massa dentro de um cálculo econômico e político. A presença da massa se reduz a uma praça de mercado. Nesse sentido, as massas foram usadas pelos estados totalitários, que aproveitam o ajuntamento de seus clientes para comprometê-los de maneira permanente com as suas intenções.

Qual a posição do escritor em relação às massas? Opondo Baudelaire a Victor Hugo, numa relação de concorrência, Benjamin critica a ambos, por não enxergarem "a aparência social que se condensa na multidão" Hugo, escritor e político de sucesso, idealizava a massa - isto é, sua clientela de leitores e eleitores - como herói. Baudelaire, sentindo o choque de que a massa não se interessava por ele, assumiu o papel de guardião do limiar que separa o individuo da multidão, opondo-Ihe a figura do herói individual. 


\section{Fim da modernidade}

Para fazer o retrato da Modernidade, Benjamin utiliza uma figura por excelência da Antiguidade clássica: o herói e sua aura. Nesse sentido, a imagem baudelaireana do artista como herói é o arcabouço do texto intitulado A Modernidade, 30 e último capítulo do ensaio de 1938. Uma seqüência benjaminiana de imagens baudelaireanas um estilo ensaístico cinematográfico - faz desfilar caracteres sociais da metrópole Paris, sobre os quais se projetam instantâneos do poeta da Modernidade. Assim, o trabalho do escritor aparece contra o fundo de massas urbanas, sendo o molde comum da figura de primeiro plano o arquétipo do herói.

O esgrimista, o flâneur o sem-posses, os filhos de camponeses depauperados obrigados a se alistarem como mercenários, miseráveis, lúmpens, proletários, assalariados, suicidas, papa-defuntos, melancólicos, inúteis, vadios, milhares de marginais, criminosos, prostitutas, lixeiros, lésbicas, dandys revolucionários - formam uma massa compacta de personagens, uma enumeraçãò caótica, através da qual o ensaísta mostra a cidade da perspectiva dos excluídos: Uma população pobre, doentia é o fundo, contra o qual se destaca a silhueta do herói. A essa imagem, Baudelaire dá uma legenda à sua maneira, apondo a palavra la modernité.

Já estamos longe da história de detetive. Baudelaire optou pelo seu avesso: o gênero da poesia do apache, em que criminosos e prostitutas, entre outros marginais, aparecem como heróis. Benjamin, que constata a continuidade do gênero, desde a época de Baudelaire até os anos de 1920 e 30, faz sua crítica. Observa ele:

"O poeta, o suplente do antigo herói, teve de recuar diante do herói moderno, cujos feitos são noticiados pela Gazette des Tribunaux"

Esse herói moderno é o criminoso. Uma nota esclarece o sentido histórico da crítica: "Três-quartos de século depois, se reatualizou o confronto do gigolô com o literato. Quando os escritores foram expulsos da Alemanha, se instaurou na literatura alemã a lenda de um Horst Wesse/" Trata-se de um gigolô, militante nazista, morto num dos combates de rua e heroificado pelo regime. No contexto histórico de uma Alemanha em que elementos do submundo dirigiam os negócios do Estado, o crítico não tinha motivos para aderir à idealização poética do apache.

Quando Benjamin fala, concomitantemente, em substituição do herói e fim da Modernidade, isso significa, historicamente: fim da República de Weimar. As previsões de Apollinaire, citadas por ele, se 


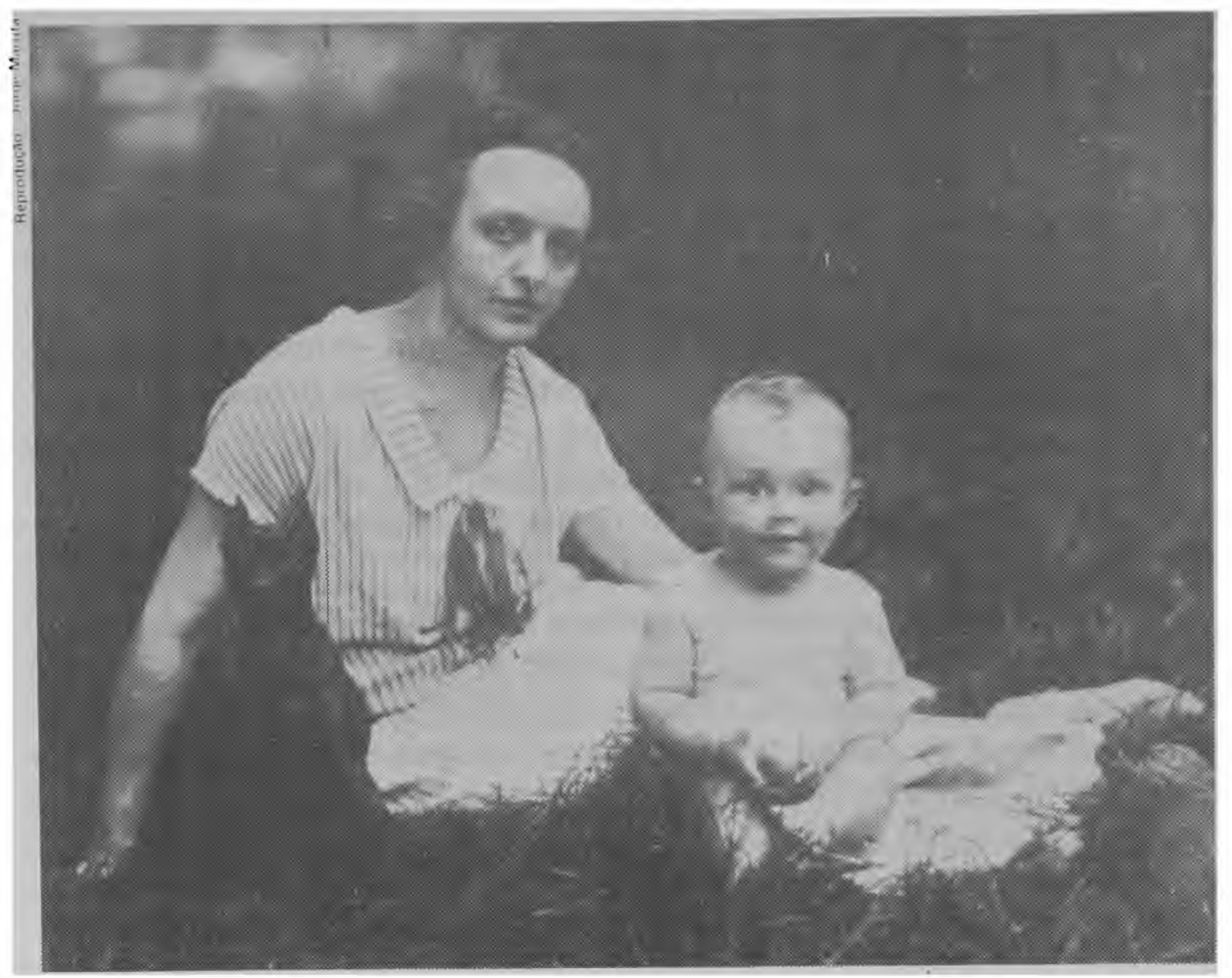

Foto 4. Mãe de classe média com seu filho, 1927/28.

cumpriram: "Editoras assa/tadas, livros queimados, poetas assassinados"; e pogroms, onde a policia "caminha junto com os saqueadores" $^{\prime \prime}$ ensaio sobre Baudelaire é a codificação do drama da literatura alemã de exílio e dos que ficaram.

Diante desse fim da Modernidade - que significava que os sonhos de uma luta pela libertação da humanidade foram sepultados Benjamin considerou como tarefa urgente do artista: "dar uma configuração à Modernidade" Nesse momento, recorre à sapiência dos antigos diante das situações de decadência, derrota e morte. O motivo baudelaireano da caducidade da metrópole, presente em poemas como Le Cygne e Les petites vieilles, é ao mesmo tempo antigo e moderno. Completando os poemas baudelaireanos com textos mais recentes, de historiadores, sociólogos, urbanistas, Benjamin faz uma montagem de visões apocalípticas. A título de exemplo, duas citações:

"Entre as necessidades do homem moderno, a do suicidio é mais forte que o instinto de autoconservação".

"Como têm crescido, juntamente com as grandes cidades, os meios para arrasá-las!" 
Na visão pessimista do crítico, a Modernidade se transforma em Trauerspiel, drama barroco, onde reina a Melancolia: A Modernidade heróica revela-se como um Trauerspiel, onde o papel do herói está à disposição. Fim da Modernidade - fim do herói. O herói não é previsto na Modernidade; ela não tem emprego para ele. Na sociedade moderna, o papel do poeta, como suplente do herói antigo, é o de um marginal. Aliás, o poeta, esse herói moderno, não é herói, é um ator que faz o papel de herói. Assim, Benjamin entendeu o trabalho poético de Baudelaire e, auto-ironicamente, o seu próprio: Flâneur, apache, dandy e lixeiro eram para ele uns tantos papéis. O trabalho do escritor moderno consiste em usar e examinar esses papéis, as máscaras da Modernidade que tapam/revelam o rosto bárbaro do humanismo no século $X X$.

Entre esses papéis consta também o do revolucionário. $O$ paralelo entre Baudelaire e Blanqui, censurado por Adorno, é a moldura do ensaio A Paris do Segundo Império em Baudelaire. "A ação de Blanqui era a irmã do sonho de Baudelaire" afirma Benjamin. O escritor guarda a memória do sonho dos derrotados. Obstinação singular, mas que tem sua razão de ser, se a palavra do poeta antigo - de que o homemé a sombra de um sonho - for o retrato real do homem moderno.

\section{Referências Bibliográficas}

1 - BENJAMIN, Walter Gesammelte Schriften. Frankfurt, Suhrkamp, 1974. v. 1, tomo 2.

2 - - Gesammelte Schriften. Frankfurt, Suhrkamp, 1982. v. 5, tomos 1 e 2.

3 - Sociologia. São Paulo, Ãtica, 1985. (Coleção Grandes Cientistas Sociais, 50).

4 - KOTHE, Flávio R. Benjamin e Adorno: confrontos. São Paulo, Ática, 1978.

5 - ROUANET, Sérgio Paulo. As razões do lluminismo. São Paulo, Companhia das Letras, 1987.

\section{FICHA CATALOGRÁFICA}

BOLLE, W. A modernidade segundo Walter Benjamin. Revista da Universidade de São Paulo. São Paulo, (5): 45-56, jun. 1987. 